\title{
Think ultrasound; could point of care ultrasound really change the management of critically ill patient?
}

\author{
Tharwat Aisa $\nabla$, Shankar Lal $\nabla$, Jubil Thomas $\nabla$, Vikash Singh Chauhan $\nabla$, \\ Nageswaran Narayanan \\ Authors' affiliation:
}

Our Lady of Lourdes Hospital Drogheda Ireland.

Correspondence: Shankar Lal; E-mail: shankar.anaesthesia1@gmail.com

\begin{abstract}
Myxomas are the most common primary cardiac neoplasms. The prevalence of cardiac tumors at autopsy ranges from $0.001 \%$ to $0.3 \%$. More than $50 \%$ of benign cardiac tumors are myxomas. Approximately $7 \%$ of these have genetic origin and arise as a component of a heritable disorder with some clinical manifestations. Over $72 \%$ of primary cardiac tumors are benign. In adults, the majority of benign lesions are myxomas. Its clinical manifestations are variable and nonspecific. Commonly observed symptoms and signs are dyspnea, orthopnea, paroxysmal nocturnal dyspnea, pulmonary edema, cough, hemoptysis, edema, and fatigue.
\end{abstract}

Key words: POCUS; ARDS; Atrial myxoma; Pulmonary edema

Abbreviations: ARDS: acute respiratory distress syndrome; CRP: C reactive protein; ABG: arterial blood gases; PEEP: positive end expiratory pressure; HFNC: high frequency nasal cannula; TTE: transthoracic echocardiography; P/F: ratio of partial pressure of oxygen to inspired oxygen fraction; CT: computed tomography; POCUS: point of care ultrasound

Citation: Aisa T, Lal S, Thomas J, Singh V, Narayanan N. Think ultrasound; could point of care ultrasound really change the management of critically ill patient? Anaesth. pain intensive care 2021;25(1):107-110; DOI: 10.35975/apic.v25i1.1438

Received: 16 June 2020; Reviewed: 4 June 2020; Accepted: 21 June 2020

\section{Introduction}

Myxomas are the most common primary cardiac neoplasms. The prevalence of cardiac tumors at autopsy ranges from $0.001 \%$ to $0.3 \%$, and more than $50 \%$ of benign cardiac tumors are myxomas. In $7 \%$, it has a genetic origin and it arises as a component of a heritable disorder with some clinical manifestations. Over $72 \%$ of primary cardiac tumors are benign. In adults, the majority of benign lesions are myxomas. ${ }^{1,2}$ The clinical manifestations are variable and nonspecific. Commonly observed symptoms and signs are dyspnea, orthopnea, paroxysmal nocturnal dyspnea, pulmonary edema, cough, hemoptysis, edema, and fatigue. ${ }^{3-5}$

Management of critically ill patients in the emergency and critical care setting is challenging and imaging techniques are essential for optimizing diagnostic and therapeutic procedures. In the last two decades the use of bedside ultrasound techniques for critically ill patient management has become popular due to the availability of less expensive and more portable ultrasound machines. Point of care ultrasound (POCUS) is increasingly being recognized as the superior imaging option in the emergency and critical care setting. ${ }^{6,7}$

We aim to report a case of critically ill patient whose management was improved thanks to the early use of POCUS at the bed side by the intensivist.

\section{Case report}

We report a case of 42-year-old male patient with a history of gout and hypercholesterolemia. He was an ex-smoker. He was admitted to the hospital ward with cough, fever, vomiting and rigors. He was hypoxic on presentation with $\mathrm{SpO}_{2} 80 \%$ on room air which was improved with oxygen $5 \mathrm{~L} / \mathrm{min}$ by mask to $94 \%$. Initial diagnosis was community acquired pneumonia. Two days later, he became more hypoxic with respiratory distress and worsening bilateral infiltrates in the chest X-ray (Figure 1). His 
laboratory findings showed leukopenia (WBC 2.6 $\mathrm{K} / \mathrm{ml})$, Hb $14.9 \mathrm{~g} / \mathrm{dl}$, neutrophils $3.5\left(10^{3} / \mu \mathrm{L}\right)$, lymphocytes $0.66\left(10^{3} / \mu \mathrm{L}\right)$, platelets $188,000 / \mu \mathrm{L}$, CRP $103 \mathrm{mg} / \mathrm{L}$, urea $7.7 \mathrm{mmol} / \mathrm{L}$, creatinine 88 $\mu \mathrm{mol} / \mathrm{L}$, sodium $138 \mathrm{mmol} / \mathrm{L}$, and influenza $\mathrm{A}+\mathrm{ve}$. His ECG showed sinus tachycardia. He was treated with ceftriaxone, clarithromycin and oseltamivir. Intensivist on call was consulted at that stage for worsening respiratory distress (respiratory rate $40 / \mathrm{min}$, heart rate 125 beats/min, desaturating on 5 $\mathrm{L} / \mathrm{min}$ oxygen), temperature $38.6^{\circ} \mathrm{C}$. He was intubated and shifted to the ICU for ventilatory support and further management. At that time the ABG results were; $\mathrm{PH} 7.36, \mathrm{PaO}_{2} 7.8 \mathrm{kPa}, \mathrm{PaCO}_{2}$ $4.8 \mathrm{kPa}$, and lactate $0.8 \mathrm{mmol} / \mathrm{L}$.

He was treated as severe ARDS as his $\mathrm{P} / \mathrm{F}$ was 58 on $\mathrm{FiO}_{2} 0.1$ and PEEP $14 \mathrm{cmH}_{2} \mathrm{O}$. Lung protective strategy was applied, sedated and paralyzed for 24 h. He remained hemodynamically stable all through. The septic screening, bronchoalveolar lavage, respiratory panel were negative except for influenza A, which was positive. Four days later, the patient started to improve in terms of ventilation parameters; $\mathrm{FiO}_{2} 45 \%$, PEEP $10 \mathrm{cmH}_{2} \mathrm{O}$ on pressure support ventilation, so weaning from the ventilator was planned.

In spite of keeping him on negative fluid balance, his oxygen requirements increased again to $\mathrm{FiO}_{2} 90 \%$, PEEP $12 \mathrm{cmH}_{2} \mathrm{O}$ and $\mathrm{P} / \mathrm{F}$ ratio 90 with radiological deterioration (worsening bilateral infiltrates) Figure 3.

Thus, bed side POCUS was done by the intensivist, which showed a big myxoma $(6 \times 4 \mathrm{~cm})$ which was attached to inter-atrial septum and protruding through the mitral valve leaflets to the left ventricle causing obstruction to the mitral flow with good systolic function (Figure 4). That could explain the reason for pulmonary edema and the deterioration which happened.

Cardiologist was contacted to confirm the findings and she did the transthoracic echocardiography (TTE) which confirmed our findings. Microbiologist escalated the antibiotic coverage and amphotericin B was added to cover the possibility of fungal endocarditis. Antibiotics were de-escalated when all cultures came negative. CT thorax was done and showed bilateral consolidations, effusion and cardiac filling defects. Transesophageal echocardiography was done and confirmed the findings.

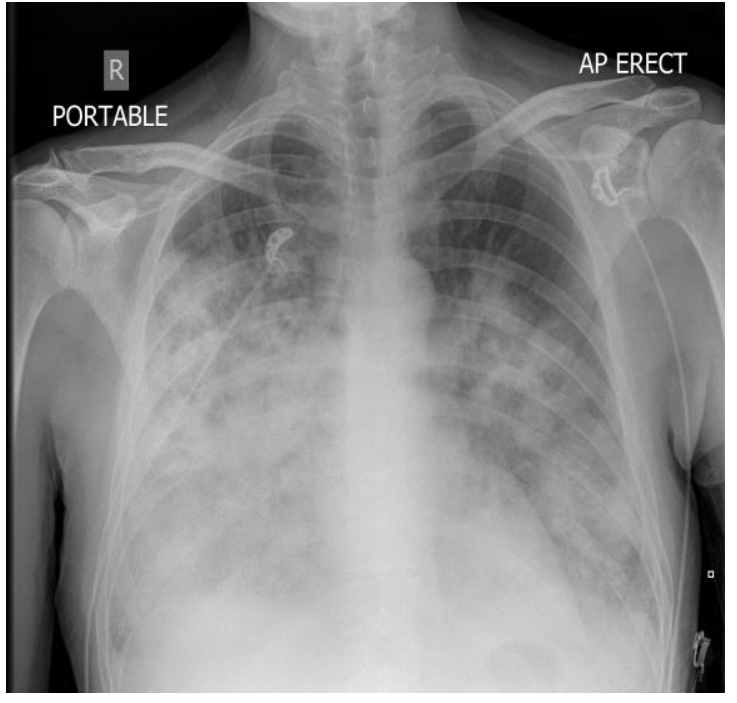

Figure 1: CXR shows bilateral lung infiltrates

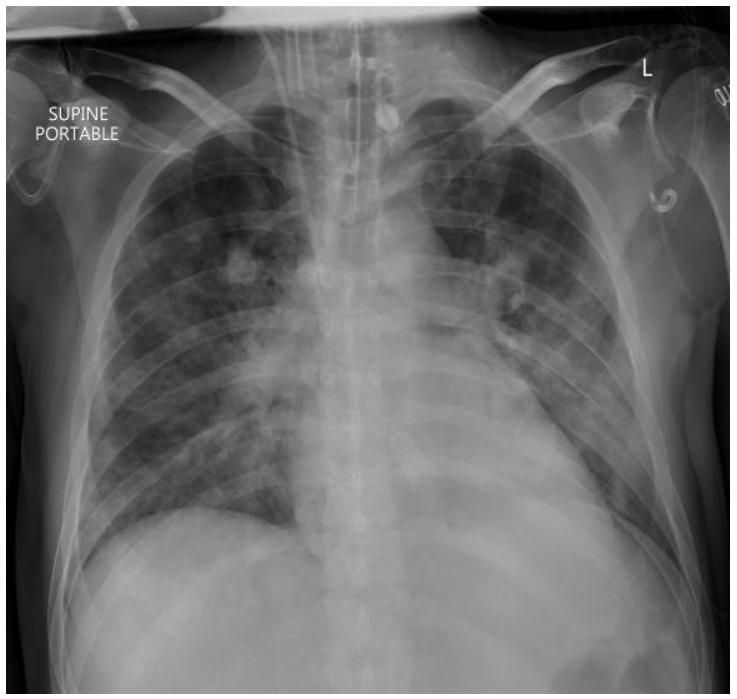

Figure 2: CXR on the day of planned extubation

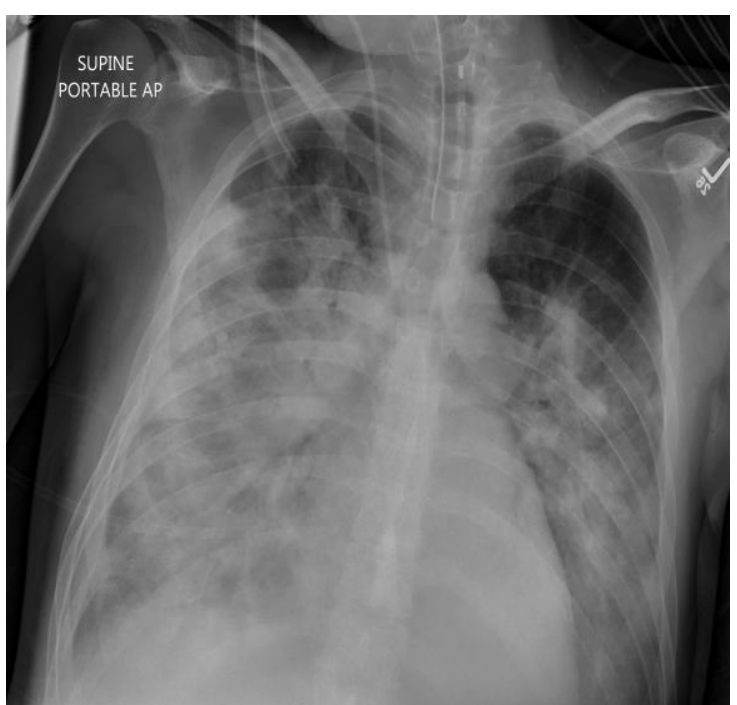

Figure 3: CXR shows worsening bilateral lung infiltrates 

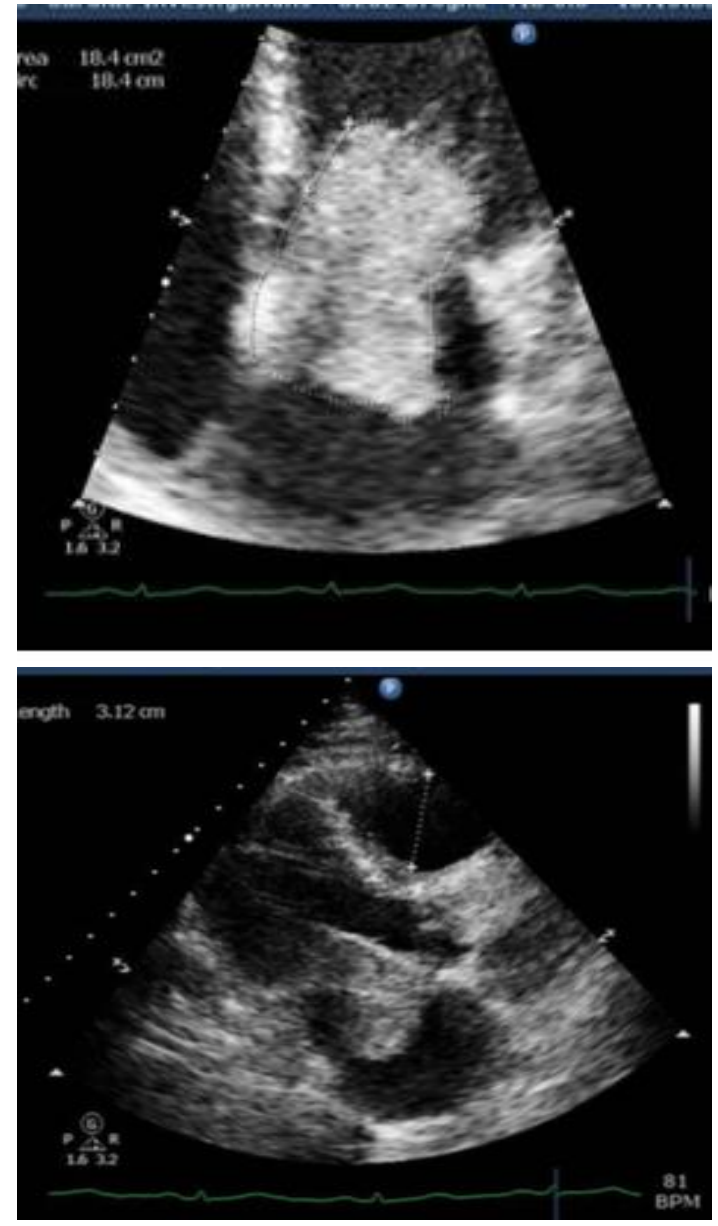

Figure 4-A \& B: Transthoracic echocardiography shows left atrial myxoma protruding through the mitral valve

5 days later, a weaning trial was done on pressure support ventilation, $\mathrm{FiO}_{2} 30 \%$ and PEEP $5 \mathrm{cmH}_{2} \mathrm{O}$. ABG showed pH 7.47, $\mathrm{PaCO}_{2} 6 \mathrm{kPa}, \mathrm{PaO}_{2} 11.6 \mathrm{kPa}$, and $\mathrm{SpO}_{2} 98 \%$. The patient was kept on negative fluid balance over the days prior to the weaning trial. He was extubated successfully and kept on HFNC $25 \%$ with good gas exchange. Tertiary care center was contacted and the patient was transferred for urgent cardiac surgery.

The surgery was done two days after the transfer and the patient was discharged home few days after that.

\section{Discussion}

The ARDS is a well-known complication of pneumonia and its management is well established. Cardiac myxomas can present with symptoms secondary to obstruction of blood flow, nonspecific constitutional symptoms such as fever, malaise, arthralgias, rash, or thromboembolic phenomena, such as stroke or transient ischemic attack. ${ }^{3,4}$ Sudden cardiac death has been reported in literature, the incidence being $0.01 \%-0.005 \%$. Syncope is reported as the most common symptom in patients with sudden cardiac death, and the cause is obstruction of blood flow either due to ball valve mechanism or due to embolization of tumor to coronary circulation. ${ }^{5}$

In our scenario, when the patient improved and was ready for extubation, he developed an acute deterioration that necessitated further investigations. The use of bedside POCUS helped us identify the cardiac myxoma as the cause of his deterioration. POCUS has the potential to optimize care of the critically ill patients when added to the clinical tools of the intensive care physician. ${ }^{8}$

Bed side echocardiography, as a part of POCUS, is widely available and provides a simple, noninvasive technique for rapid evaluation of the cardiac function in addition to detection of any underlying pathology which might contribute to the patient's sudden deterioration. TTE is sufficient to confirm the diagnosis of atrial myxoma. ${ }^{9}$

Obstructing left atrial myxoma is reported in many cases as a cause of cardiogenic pulmonary edema. ${ }^{10-}$ 13 Moreover, echocardiography helps in distinguishing a cardiac myxomas from an atrial thrombus. A thrombus usually arises from the posterior wall of the atrium and is generally immobile and does not have the characteristic stalk. ${ }^{4}$ In our patient, the cardiac mass was pedunculated with a stalk arising from the interatrial septum which is the common site of origin of an atrial myxoma. Its definitive treatment is surgical excision.

\section{Conclusion}

Cardiac masses are rare, and they could present with obstructive shock or pulmonary edema which might complicate the course of a disease like ARDS. They need to be diagnosed at the earliest, so as to initiate timely interventions. Echocardiography remains the only modality which makes a point of care diagnosis in cases of cardiac masses and makes an invaluable tool in the armament of an intensivist. This case, however; highlights the importance to equip intensivists, the anesthetists and emergency physicians with point of care ultrasound skills to help in the diagnosis of such cases with confidence.

\section{Conflict of interest}

None declared by the authors. 


\section{Authors" contribution}

All authors took part in the management of the case, report writing, literature search and the drafting.

\section{References}

1. Yu K, Liu Y, Wang H, Hu S, Long C. Epidemiological and pathological characteristics of cardiac tumors: a clinical study of 242 cases. Interact Cardiovasc Thorac Surg. 2007;6(5):636-639. [PubMed] DOI: 10.1510/icvts.2007.156554

2. Amano J, Kono T, Wada Y, Zhang T, Koide N, Fujimori $\mathrm{M}$, et al. Cardiac myxoma: its origin and tumor characteristics. Ann Thorac Cardiovasc Surg. 2003;9(4):215-221. [PubMed]

3. Negi RC, Chauhan V, Sharma B, Bhardwaj R, Thakur S. Atrial myxoma: A rare cause of ischemic stroke. J Assoc Physicians India. 2013;61:280-282. [PubMed]

4. Singh PK, Sureka RK, Sharma AK, Bhuyan S, Gupta $V$. Recurrent stroke in a case of left atrial myxoma masquerading vasculitis. J Assoc Physicians India. 2013;61:912, 917-920. [PubMed]

5. Modi K, Venkatesh P, Agnani S, Rowland T, Reddy P. Sudden death in a patient with left atrial myxoma: Report of two cases and review of literature. BJMP. 2013;3:318-321. [FreeFullText]

6. Volpicelli G, Elbarbary M, Blaivas M, Lichtenstein DA, Mathis G, Kirkpatrick AW, et al. International evidence-based recommendations for point-of-care lung ultrasound. Intens Care Med. 2012;38:577-91. [PubMed] DOI: 10.1007/s00134-012-2513-4
7. Bouhemad B, Zhang M, Lu Q, Rouby JJ. Clinical review: Bedside lung ultrasound in critical care practice. Crit Care. 2007;11(1):205. [PubMed] DOI: $\underline{10.1186 / \operatorname{cc} 5668}$

8. Bernier-Jean A, Albert M, Shiloh AL, Eisen LA, Williamson D, Beaulieu Y. The Diagnostic and Therapeutic Impact of Point-of-Care Ultrasonography in the Intensive Care Unit. J Intensive Care Med. 2017 Mar;32(3):197-203. [PubMed] DOI: $\underline{10.1177 / 0885066615606682}$

9. Yoo M, Graybeal DF. An echocardiographicconfirmed case of atrial myxoma causing cerebral embolic ischemic stroke: a case report. Cases J. 2008;1(1):96. [PubMed] DOI: 10.1186/1757-1626-1$\underline{96}$

10. La Lai R, Lee CP, Tan C, et al. Case Report: Large Left Atrial Myxoma Presenting as Pneumonia and Acute Respiratory Distress Syndrome, Am J of Respir Crit Care Med 2016;193:A6981. [FreeFullText]

11. Aggarwal SK, Barik R, Sarma TC, lyer VR, Sai V, Mishra J, et al. Clinical presentation and investigation findings in cardiac myxomas: new insights from the developing world. Am Heart J. 2007;154(6):11021107. [PubMed] DOI: $10.1016 /$ j.ahj.2007.07.032

12. Pinede $L$, Duhaut $P$, Loire $R$. Clinical presentation of left atrial cardiac myxoma: a series of 112 consecutive cases. Medicine. 2001;80(3):159-172. [PubMed] DOI: 10.1097/00005792-200105000-00002

13. Demir M, Akpinar $O$, Acarturk E. Atrial myxoma: an unusual cause of myocardial infarction. Tex Heart Inst J. 2005;32(3):445-447. [PubMed] 